\title{
PEMBANGUNAN WILAYAH PESISIR BERORIENTASI INDEKS PEMBANGUNAN MANUSIA (IPM) MELALUI PENGUATAN KOORDINASI FUNGSIONAL RENCANA KERJA PEMERINTAH DAERAH (RKPD) (Studi Kasus di Kabupaten Sambas, Kalimantan Barat) Strenghtening of Coordination of Functional Work Plan of Local Government (RKPD) Through Development Coastal Areas Based on Human Development Index (A Case Study in Sambas Regency, West Kalimantan)
}

\author{
"Suwarli' dan Maulana Firdaus² \\ 'Badan Pengembangan Sumber Daya Manusia Kementerian Dalam Negeri \\ Jalan Kompleks Taman Makam Pahlawan No.8, Kalibata, Kota Jakarta Selatan, \\ Daerah Khusus Ibukota Jakarta 12740 \\ ${ }^{2}$ Balai Besar Riset Sosial Ekonomi Kelautan dan Perikanan \\ Diterima tanggal: 16 Maret 2017 Diterima setelah perbaikan: 13 April 2017 \\ Disetujui terbit: 6 Juni 2017 \\ email: war_suwarli@yahoo.com
}

\begin{abstract}
ABSTRAK
Pembangunan wilayah pesisir dan perbatasan memiliki banyak tantangan dan permasalahan, diantaranya adalah ketidakselarasan antara pemerintah pusat dan daerah. Rendahnya nilai akuntabilitas kinerja pembangunan yang termuat dalam Rencana Kerja Pembangunan Daerah (RKPD) adalah salah satunya. Penelitian ini bertujuan untuk menganalisis tingkat penguatan koordinasi fungsional terhadap RKPD yang berorientasi pada percepatan pencapaian Indeks Pembangunan Manusia (IPM). Penelitian ini dilaksanakan pada bulan Maret - Juni 2016. Lokasi penelitian di Kabupaten Sambas yang merupakan wilayah pesisir dan perbatasan dengan potensi sumber daya perikanan yang cukup besar. Data primer dan sekunder digunakan dalam penelitian ini. Penelitian ini menggunakan metode survey dengan angket sebagai alat bantu pengumpulan data. Informan dipilih secara purposive sampling sebanyak 42 orang pejabat struktural lingkup Satuan Kerja Perangkat Daerah (SKPD) di Kabupaten Sambas. Data kualitatif dianalisis secara deskriptif dan data yang bersifat kuantitatif dianalisis dengan pendekatan statistik. Hasil penelitian menunjukkan bahwa pembangunan manusia di Kabupaten Sambas fluktuatif dalam periode 2010 - 2015, namun secara agregat mengalami peningkatan. Penurunan tingkat kesejahteraan dicerminkan oleh nilai IPM berkorelasi dengan penurunan laju pertumbuhan nilai Produk Domestik Regional Bruto (PDRB) per kapita. Laju pertumbuhan PDRB sub sektor perikanan terus meningkat yang menandakan bahwa sub sektor perikanan lebih stabil dan dapat diandalkan sebagai sub sektor unggulan. Hasil analisis penguatan koordinasi fungsional RKPD menunjukkan bahwa koordinasi lingkup SKPD di Kabupaten Sambas sudah memiliki kinerja yang baik, yaitu dengan rata-rata nilai skor secara keseluruhan adalah 2,32 (77,21\%) dan masuk ke dalam klasifikasi "kuat". Kinerja yang baik ini dapat menjadi modal utama dalam proses perencanaan pembangunan Kabupaten Sambas sebagai wilayah pesisir dan perbatasan sehingga dapat menjadikan Kabupaten Sambas sebagai salah satu wilayah perbatasan yang berkembang.
\end{abstract}

Kata Kunci: RKPD,koordinasi fungsional, pesisir, IPM

\section{ABSTRACT}

Development of coastal areas and the border has many challenges and problems, including the lack of central and local governments policys. The low performance accountability of development policy in RKPD is one of the issues. This study aimed to analyze the level of functional coordination strengthening against RKPD oriented to accelerate the achievement of Human Development Index (HDI). This study was conducted in March-June 2016. The research location in Sambas Regency which is the border with the coastal areas and has its potential fisheries resource. Primary and secondary data were used in this study. This study uses a survey by questionnaire as a tool for data collection. The informan chosen by 
purposive sampling as many as 42 people SKPD scope of structural officials in Sambas regency. Data were analyzed descriptively qualitative and quantitative data was analyzed by a statistical approach. The results showed that the human development index in Sambas regency fluctuated in the period 2010 - 2015, aggregatlye increased. Decreased levels of well-being mirrored by HDI value correlates with decreased growth rate in the value of GDP per capita. GDP growth rate fisheries sub-sector continues to increase indicating that the fisheries sub-sector is more stable and reliable as the leading sector. The results of the analysis of functional coordination enhancement RKPD show that the coordination sphere SKPD in Sambas district already has a good performance, with an average value of the overall score was 2.32 (77.21\%) and can be classified as "strong". This good performance can be a major capital in Sambas district development planning process as coastal and border regions in order to make Sambas district became one of the developing border areas.

Keywords: RKPD, functional coordination,coastal, IPM

\section{PENDAHULUAN}

Pembangunan wilayah pesisir di Indonesia memiliki banyak tantangan dan permasalahan. Wiranto (2004), mengatakan bahwa pembangunan wilayah pesisir memiliki beberapa permasalahan, antara lain tidak sinkronnya hubungan antara daerah dan pusat, pembangunan ekonomi terkait kemiskinan serta eksploitasi sumber daya alam tanpa memperhatikan kelestariannya. Permasalahan umum yang banyak terjadi dibeberapa wilayah pesisir di Indonesia yaitu terkait hubungan antara pemerintah pusat dan daerah yaitu kurang selarasnya pemenuhan kepentingan pusat dan daerah. Hal ini pun terjadi pada proses pembangunan di Kabupaten Sambas, dimana seringkali instansi dinas di kabupaten telah memiliki tugas pokok dan fungsi organisasi, namun belum memiliki kewenangan teknis karena belum ada penyerahan kewenangan dari pusat dan propinsi (Badan Perencanaan Pembangunan Daerah (Bappeda) Kabupaten Sambas, 2015).

Kabupaten Sambas merupakan salah satu wilayah pesisir di Indonesia dengan panjang pantai 198,76 km, panjang perbatasan negara sepanjang $97 \mathrm{~km}$ dan nilai produksi perikanan laut pada tahun 2014 sebesar 1,167 Triliun (Badan Pusat Statistik (BPS) Kabupaten Sambas, 2015). Potensi ini menunjukkan bahwa cukup besar ketergantungan masyarakat wilayah tersebut terhadap sumber daya pesisir dan usaha pada sektor perikanan. Permasalahan pembangunan di Kabupaten Sambas juga tidak terlepas dari letak geografisnya yang berbatasan langsung dengan Negara Malaysia. Sebagai salah satu wilayah perbatasan di Indonesia, isu pengembangan wilayah perbatasan (antar negara) semakin krusial dan perlu mendapatkan perhatian serius dari pemerintah (Lembaga IImu Pengetahuan Indonesia
(LIPI), 2003). Pembangunan sosial ekonomi di wilayah perbatasan cenderung terabaikan sehingga wilayah perbatasan masuk dalam kategori wilayah tertinggal.

Kurang selarasnya pemenuhan kepentingan pusat dan daerah tidak terlepas dari rendahnya tingkat kepercayaan pemerintah pusat terhadap berjalannya pembangunan di daerah. Apa yang direncanakan dengan apa yang diimplementasikan dinilai belum selaras. Hal ini diperparah dengan masih rendahnya nilai akuntabilitas kinerja pembangunan akibat pencapaian target rencana tahunan yang termuat dalam Rencana Kerja Pembangunan Daerah (RKPD) yang tidak memenuhi target sesuai Rencana Pembangunan Jangka Menengah Daerah (RPJMD).

Hasil publikasi nilai akuntabilitas dari Kementerian Pendayagunaan Aparatur Negara dan Reformasi Birokrasi (KEMENPAN \& RB) tahun 2015 menunjukkan bahwa 34 Pemerintah Daerah Provinsi di Indonesia tidak satupun memiliki nilai yang memuaskan. Hal ini dapat mengindikasikan masih rendahnya sikap pertanggungjawaban terhadap tujuan pembangunan itu sendiri khususnya berbasis Indeks Pembangunan Manusia (IPM). IPM merupakan ukuran keberhasilan yang diungkapkan kedalam nilai capaian indikator pembangunan yaitu berupa derajat kesehatan yang ditandai umur panjang, tingkat pengetahuan yang tinggi dan kehidupan yang layak.

Hasil penelitian yang dilakukan oleh Yacoub (2012) menunjukkan bahwa rata-rata tingkat kemiskinan di Kabupaten Sambas periode 2005-2010 yaitu sebesar 12,90\%, dimana nilai ini berada di atas rata-rata tingkat kemiskinan Provinsi Kalimantan Barat yang sebesar 11,90. Kemiskinan menjadi persoalan mendasar dalam proses pembangunan. Menurut Sjafii (2009) kemiskinan 
tidak terlepas dari peranan pemerintah dan swasta yang mengalokasikan investasi maupun belanja daerahnya untuk meningkatkan kualitas modal manusia. Alokasi belanja daerah yang tersusun dalam Rencana Kerja Pembangunan Daerah (RKPD), setidaknya dalam RKPD ini haruslah berorientasi juga terhadap peningkatan kualitas modal manusia. Tingkat pembangunan manusia yang relatif tinggi akan mempengaruhi kinerja pertumbuhan ekonomi melalui kapabilitas penduduk dan konsekuensinya adalah peningkatan produktivitas dan kreativitas masyarakat. Meningkatnya produktivitas dan kreativitas tersebut, penduduk dapat menyerap dan mengelola sumber daya yang penting bagi pertumbuhan ekonomi (Brata, 2005).

Penelitian terkait penguatan koordinasi fungsional Rencana Kerja Pemerintah Daerah (RKPD) untuk pembangunan berbasis IPM dinilai sangat strategis untuk dilakukan. Hal ini sebagai salah satu upaya untuk mencapai tujuan pembangunan di wilayah perbatasan khususnya di Kabupaten Sambas yang merupakan wilayah pesisir yang memiliki tantangan dan permasalahan yang kompleks. Wilayah perbatasan yang selalu identik dengan ketertinggalan diharapkan dapat mencapai tujuan pembangunan melalui konsep pembangunan manusia yang menitikberatkan pada pembangunan sumber daya manusia yang seiring dengan pertumbuhan ekonomi. Keberhasilan pembangunan wilayah pesisir perbatasan tidak terlepas dari peranan pemerintah pusat dan antar Satuan Kerja Perangkat Daerah (SKPD) yang selaras. Berdasarkan hal tersebut maka tujuan dari penelitian ini adalah untuk menganalisis tingkat penguatan koordinasi fungsional terhadap dokumen perencanaan tahunan RKPD Kabupaten Sambas sejak tahap awal penyusunan, evaluasi pelaksanaan, dan evaluasi hasil serta menganalisis tingkat pemahaman sumber daya manusia perencana dalam penyusunan dokumen RKPD yang berorientasi pada percepatan pencapaian IPM.

\section{METODOLOGI}

Penelitian ini bersifat kualitatif, dimana melibatkan interpretasi dan pendekatan naturalistik terhadap subjek penelitian serta menggunakan berbagai metode atau pendekatan pada satu fokus kajian (Denzin dan Lincoln, 1994). Sementara itu studi kasus digunakan untuk membatasi fokus dan subjek penelitian pada hal-hal atau kasus yang terkait dengan penguatan koordinasi fungsional Rencana Kerja Pemerintah Daerah (RKPD) untuk pembangunan berbasis IPM. Studi kasus yang dilakukan yaitu bersifat studi kasus mendalam (intrinsic case study). Hal ini dilakukan tidak dengan maksud untuk menempatkan kasus tersebut mewakili dari kasus lain, tetapi tidak menutup kemungkinan pada lokasi yang berbeda mengalami kasus yang sama. Pada umumnya, para peneliti studi kasus mendalam bermaksud untuk meneliti atau menggali hal-hal yang mendasar yang berada di balik kasus tersebut (Stake, 2005).

\section{Lokasi dan Waktu Penelitian}

Penelitian ini dilakukan di Kabupaten Sambas, Provinsi Kalimantan Barat. Periode pelaksanaan penelitian yaitu pada Bulan Maret sampai dengan Juni 2016. Kabupaten Sambas dipilih menjadi lokasi penelitian karena merupakan salah satu sentra perikanan tangkap di Kalimantan Barat. Selain itu, kabupaten ini secara geografis merupakan wilayah pesisir dan perbatasan yang berbatasan langsung dengan Negara Malaysia.

\section{Jenis dan Sumber Data}

Berdasarkan jenisnya, data yang digunakan dalam penelitian ini terdiri dari data primer dan data sekunder. Data primer yang dikumpulkan terdiri dari karakteristik informan, keterlibatan dalam penyusunan RKPD, mekanisme koordinasi dan informasi terkait evaluasi hasil RKPD di lingkup Kabupaten Sambas. Data sekunder yang dikumpulkan berupa beberapa laporan tahunan SKPD lingkup Kabupaten Sambas, data demografi, potensi sumber daya perikanan, peraturan daerah lingkup Kabupaten Sambas dan data lainnya yang mendukung tujuan penelitian.

Data primer dilakukan melalui survey dengan alat bantu angket. Angket merupakan teknik pengumpulan data yang dilakukan dengan mengadakan komunikasi dengan sumber data (Emzir, 2008). Angket ini diberikan kepada informan dalam hal ini adalah pejabat struktural SKPD lingkup Kabupaten Sambas. Variabel yang ditanyakan dalam angket berupa pelaksanaan koordinasi penyusunan, pengendalian dan evaluasi RKPD di Kabupaten Sambas. Pemilihan informan dengan menggunakan teknik purposive sampling. Jumlah informan dalam penelitian ini adalah sebanyak 42 orang yang berasal dari Dinas atau Badan dan Kecamatan (Unit Pelaksana Teknis (UPT), Badan Layanan Umum Daerah (BLUD) dan Rumah Sakit 
Umum Daerah (RSUD). SKPD yang dipilih adalah unit organisasi yang secara representatif dapat memberikan informasi dan terlibat secara langsung dalam sinergitas penyusunan perencanaan dokumen RKPD. Data sekunder diperoleh dari penelusuran hasil penelitian sejenis, regulasi dan buku-buku literatur terkait perencanaan pembangunan baik dari SKPD lingkup Kabupaten Sambas dan Badan Pusat Statistik.

\section{Metode Analisis Data}

Teknik analisis data yang digunakan dalam penelitian kualitatif mencakup transkrip hasil wawancara, reduksi data, analisis, interpretasi data dan triangulasi. Data kualitatif dianalisis secara deskripsi dan data yang bersifat kuantitatif melalui teknik angket dianalisis dengan menggunakan pendekatan statistik. Dalam melakukan analisis terhadap koordinasi fungsional rancangan awal SKPD dan analisis penguatan koordinasi penguatan fungsional penyusunan RKPD, indikator yang telah dibangun terkait koordinasi dan penguatan fungsional RKPD untuk langkah pertama dilakukan penentuan bobot, nilai dan skor.

Bobot ditentukan berdasarkan tingkat kepentingan atau urgensi indikator penguatan koordinasi dengan skala 1 sampai 5 ( 1 = tidak penting, 5 = sangat penting). Langkah kedua adalah menentukan nilai. Nilai diperoleh dari hasil kuantifikasi dari data yang diperoleh. Rentang nilai berkisar antara 1 sampai dengan 3. Nilai skor diperoleh berdasarkan hasil bobot dikali nilai (bobot $x$ nilai). Total nilai skor untuk indikator menunjukkan bahwa semakin nilainya mendekati 3 , semakin baik dan jika semakin kecil atau mendekati 1 berarti indikator tersebut kurang baik atau banyak kelemahannya. Pengklasifikasian kategori atribut ditampilkan pada Tabel 1.

\section{HASIL DAN PEMBAHASAN}

\section{Indeks Pembangunan Manusia di Kabupaten Sambas}

Terdapat tiga indikator terpenting yang dijadikan tolak ukur untuk menyusun Indeks Pembangunan Manusia (IPM). Pertama, usia panjang yang diukur dengan rata-rata lama hidup pendudukatau angka harapan hidup di suatu negara. Kedua, pengetahuan yang diukur dengan rata-rata tertimbang dari jumlah orang dewasa yang bisa membaca (diberi bobot dua per tiga) dan rata-rata tahun sekolah (diberi bobot sepertiga). Ketiga, penghasilan yang diukur dengan pendapatan per kapita riil yang telah disesuaikan daya belinya untuk tiap wilayah. IPM merupakan indikator penting untuk mengukur keberhasilan dalam upaya membangun kualitas hidup manusia (masyarakat/ penduduk). IPM menjelaskan bagaimana penduduk dapat mengakses hasil pembangunan dalam memperoleh pendapatan, kesehatan, pendidikan, dan sebagainya (Putra \& Ulupui, 2015).

Kemajuan pembangunan manusia di Kabupaten Sambas dapat dilihat melalui dua aspek yaitu kecepatan dan status pencapaian. Secara umum, pembangunan manusia di Kabupaten Sambas terus mengalami peningkatan, hal ini dapat dilihat dari angka capaian IPM yakni dari nilai sebesar 59,81 (2010) menjadi 63,28 (2014). Selama kurun waktu 5 (lima) tahun pencapaian IPM Kabupaten Sambas menempati peringkat ke-6 (2014) se Provinsi Kalimantan Barat. Pada tahun 2015 IPM Kabupaten Sambas mengalami peningkatan dari nilai sebesar 63,28 menjadi 64,14, namun turun satu peringkat menjadi ke-7. Ada hal yang menarik pada periode 2013-2014 dimana nilai IPM seluruh kabupaten/kota di Kalimantan Barat mengalami penurunan. Untuk Kabupaten

Tabel 1. Klasifikasi Penghitungan Persentase Pencapaian Skor Koordinasi dan Penguatan RKPD di Kabupaten Sambas, 2016.

Table 1. Classification of Percentage Calculation of the Coordination and Strengthening RKPD Achievement Score in Sambas Regency, 2016.

\begin{tabular}{cc}
\hline Klasifikasi (\%) / Classifications & Atribut / Atribute \\
\hline $91-100$ & Sangat kuat/Very strong \\
$76-90$ & Kuat/Strong \\
$61-75$ & Cukup kuat/Strong enough \\
$51-60$ & Kurang kuat/Less powerful \\
$<50$ & Tidak kuat/Weak \\
\hline
\end{tabular}


Sambas menurun sekitar 3 poin dari 66,81 menjadi 63,28. Penurunan IPM ini menunjukkan adanya penurunan tingkat kesejahteraan secara agregat untuk masyarakat di Kabupaten Sambas (Tabel 2).

Penurunan tingkat kesejahteraan dapat berupa penurunan kualitas kesehatan, penurunan tingkat pendapatan dan daya beli masyarakat. Salah satu indikator yang dapat digunakan untuk mengukur tingkat kesejahteraan masyarakat dalam suatu daerah dapat dilihat melalui Produk Domestik Regional Bruto (PDRB) per kapita. PDRB merupakan nilai tambah bruto seluruh barang dan jasa yang tercipta atau dihasilkan di wilayah domestik (kabupaten/kota) suatu negara yang timbul akibat berbagai aktivitas ekonomi dalam suatu periode tertentu tanpa memperhatikan apakah faktor produksi yang dimiliki residen atau non-residen. Hasil studi yang dilakukan oleh Hwa (2005) dalam Sjafii (2009) menunjukkan bahwa adanya kaitan yang erat antara pertumbuhan ekonomi dan pembangunan manusia. Pertumbuhan ekonomi akan menjadikan pembangunan manusia menjadi semakin baik. Perbaikan kualitas manusia tersebut dalam jangka panjang akan menjadikan kinerja perekonomian akan meningkat.

Struktur perekonomian di Kabupaten Sambas utamanya ditunjang oleh sektor pertanian, kehutanan dan perikanan. Hal ini menunjukkan bahwa banyak masyarakat yang tergantung pada sektor tersebut. Jika dikaitkan antara penurunan IPM periode 2013-2014 dengan laju pertumbuhan PDRB per kapita sektoral di Kabupaten Sambas diketahui bahwa PDRB per kapita sektoral khususnya untuk sektor pertanian, kehutanan dan perikanan juga mengalami penurunan (Tabel 3). Penurunan laju pertumbuhan PDRB per kapita yaitu utamanya terjadi pada sub sektor pertanian dan kehutanan sedangkan untuk sub sektor perikanan mengalami peningkatan sekitar 12\% jauh lebih besar dibandingkan peningkatan laju pertumbuhan PDRB per kapita agregat semua sektor yang nilainya kurang dari $1 \%$. Peningkatan nilai PDRB pada sub sektor perikanan menunjukkan Kabupaten Sambas merupakan wilayah pesisir dengan potensi sumber daya ikan yang besar. Hal ini juga diperkuat dengan nilai laju pertumbuhan rata-rata periode 2011-2015 yang bernilai positif sedangkan untuk sektor lainnya negatif sehingga sektor perikanan dapat diandalkan sebagai salah satu motor penggerak pembangunan. Berdasarkan data BPS tahun 2013 diketahui bahwa nilai PDRB sub sektor perikanan di Kabupaten Sambas mencapai 466,57 milyar rupiah atau berkontribusi sebesar $0,052 \%$ terhadap total PDRB. Kontribusi sektor perikanan terhadap PDRB masih lebih tinggi dibandingkan pada sektor kehutanan dan pertambangan. Dimana pada umumnya untuk sektor kehutanan dan pertambangan di wilayah kalimantan menjadi unggulan. Besarnya potensi perikanan di Kabupaten Sambas tidak terlepas dari adanya program pemberdayaan masyarakat "minapolitan" berbasis perikanan tangkap pada tahun 2011 dari Kementerian Kelautan dan Perikanan. Program ini merupakan salah satu program untuk peningkatan kesejahteraan nelayan dan masyarakat pesisir.

Teori pertumbuhan menekankan pentingnya peranan pemerintah dalam meningkatkan pembangunan modal manusia. Peningkatan pembangunan modal manusia dapat mendorong produktivitas seseorang sehingga mampu mengurangi angka kemiskinan (Suliswanto, 2010). Peningkatan nilai PDRB sub sektor perikanan dapat menunjukkan adanya peningkatan kualitas hidup dan kesejahteraan masyarakat yang bergantung pada sub sektor perikanan. Peningkatan PDRB akan memicu peningkatan IPM di Kabupaten Sambas dan pada akhirnya akan mengurangi tingkat kemiskinan. Sejalan dengan studi yang dilakukan oleh Sitepu dan Sinaga (2012) bahwa peningkatan sumber daya manusia dapat menurunkan poverty incidence, poverty depth dan poverty severity.

\section{Penguatan Koordinasi Fungsional Rencana Kerja Pemerintah Daerah (RKPD)}

Penguatan koordinasi fungsional RKPD di Kabupaten Sambas dalam kajian ini dibagi menjadi empat tahapan, yaitu tahapan pengendalian rancangan awal RKPD, mekanisme koordinasi pengendalian pelaksanaan RKPD, mekanisme koordinasi evaluasi hasil RKPD dan mekanisme pelaksanaan koordinasi pembangunan. Pengendalian rancangan awal RKPD adalah untuk menjamin bahwa RKPD telah disusun sesuai dengan tahapan dan tata cara penyusunan RKPD yang diatur dalam peraturan perundang-undangan, serta selaras dengan prioritas dan sasaran pembangunan nasional dan RKPD, RPJMD serta RENSTRARENJA SKPD. Pengendalian pelaksanaan RKPD dimaksudkan untuk menjamin bahwa prioritas dan sasaran pembangunan tahunan daerah, rencana program dan kegiatan prioritas daerah serta pagu indikatif yang ditetapkan dalam RKPD, dijadikan pedoman penyusunan rancangan KUA, PPAS dan APBD. Tujuan mekanisme evaluasi hasil RKPD 


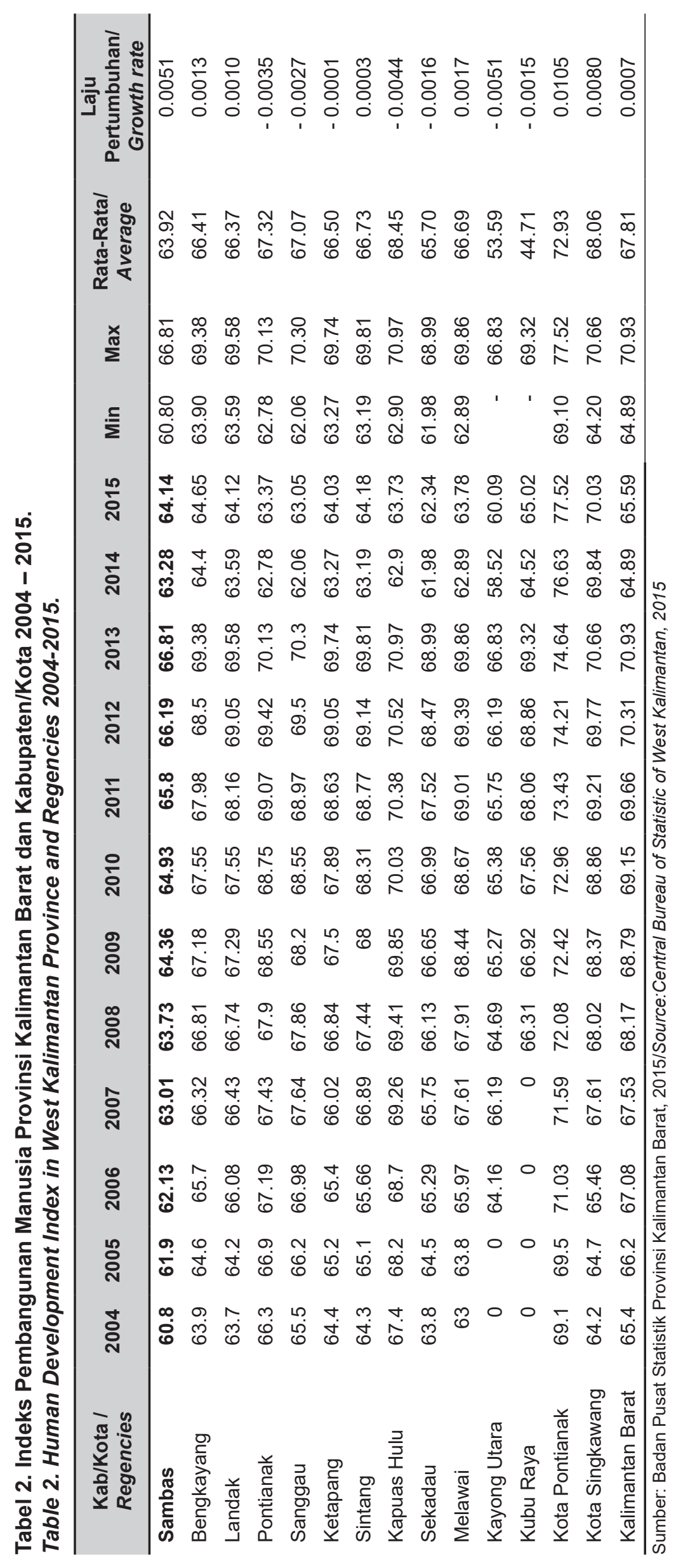


Tabel 3. Laju Pertumbuhan Produk Domestik Regional Bruto Per Kapita Kabupaten Sambas Atas Dasar Harga Berlaku menurut Lapangan Usaha (\%), 2011 - 2015.

Table 3. Growth Rate of the Per Capita Gross Regional Domestic Product of Sambas Regency at Current Market Prices by Industry (percent), 2011-2015.

\begin{tabular}{|c|c|c|c|c|c|c|c|}
\hline No & Lapangan Usaha/ Industry & 2011 & 2012 & 2013 & 2014 & 2015 & $\begin{array}{c}\text { Laju Pertumbuhan } \\
\text { Rata-rata (\%/Thn)I } \\
\text { Average Growth } \\
\text { Rate }(\% / \text { Year) }\end{array}$ \\
\hline \multirow[t]{4}{*}{1} & $\begin{array}{l}\text { Pertanian, Kehutanan dan Perikanan/ } \\
\text { Agriculture, Forestry and Fisheries }\end{array}$ & 11.2 & 5.34 & 8.11 & 7.46 & 8.89 & -0.19 \\
\hline & $\begin{array}{l}\text { 1. Pertanian, Peternakan, Perburuan } \\
\text { dan Jasa Pertanian/Agriculture, } \\
\text { Livestock, Hunting and Agriculture } \\
\text { Services }\end{array}$ & 11.68 & 4.8 & 9.04 & 6.63 & 8.98 & -0.14 \\
\hline & $\begin{array}{l}\text { 2. Kehutanan dan Penebangan Kayu/ } \\
\text { Forestry and Logging }\end{array}$ & 4.03 & 5.46 & 0.7 & -5.63 & 4.07 & -2.44 \\
\hline & 3. Perikanan/Fisheries & 9.43 & 8.91 & 3.47 & 15.39 & 9.02 & 0.27 \\
\hline 2 & $\begin{array}{l}\text { Pengadaan Listrik dan Gas/Electricity } \\
\text { and Gas }\end{array}$ & -0.42 & 7.32 & 5.22 & 14.45 & 6.52 & -4.26 \\
\hline 3 & $\begin{array}{l}\text { Pengadaan Air, Pengelolaan } \\
\text { Sampah, Limbah dan Daur Ulang/ } \\
\text { Water Supply, Sewerage, Waste } \\
\text { Management and Remediation } \\
\text { Activities. }\end{array}$ & 12.11 & 4.28 & -0.41 & 8.44 & 5.75 & -4.95 \\
\hline 4 & $\begin{array}{l}\text { Transportasi dan Pergudangan/ } \\
\text { Transportation and Storage. }\end{array}$ & 10.81 & 10.41 & 11.58 & 10.86 & 9.71 & -0.22 \\
\hline 5 & $\begin{array}{l}\text { Penyediaan Akomodasi dan Makan } \\
\text { Minum/Accommodation and Food } \\
\text { Service Activities }\end{array}$ & 9.6 & 11.83 & 10.17 & 11.49 & 13.11 & -0.12 \\
\hline 6 & $\begin{array}{l}\text { Informasi dan Komunikasi/ } \\
\text { Information and Communication }\end{array}$ & 9 & 6.9 & 5.69 & 9.79 & 12.11 & -0.09 \\
\hline 7 & Real Estate/Real Estate Activities & 10.61 & 12.54 & 11.42 & 10.1 & 8.9 & -0.22 \\
\hline 8 & Jasa Pendidikan/Education & 12.89 & 11.14 & 12.59 & 12.64 & 10.78 & -0.23 \\
\hline 9 & $\begin{array}{l}\text { Jasa Kesehatan dan Kegiatan Sosial/ } \\
\text { Human Health and Social Work } \\
\text { Activities }\end{array}$ & 13.16 & 10.65 & 10.03 & 11.41 & 10.39 & -0.24 \\
\hline
\end{tabular}

Sumber: Badan Pusat Statistik Kabupaten Sambas, 2015/Source: Central Bureau of Statistic, 2015.

adalah untuk memastikan dan menilai bahwa target program dan kegiatan prioritas daerah dalam RKPD dapat dicapai dalam rangka mewujudkan sasaran pembangunan jangka menengah daerah khususnya pembangunan berbasis IPM.

Dari setiap tahapan penguatan koordinasi fungsional RKPD memiliki indikator-indikator yang diukur dapat mencerminkan sisi perencanaan pembangunan berbasis IPM. Berdasarkan hasil analisis diketahui bahwa penguatan koordinasi pengendalian rumusan rancangan awal RKPD dalam perencanaan pembangunan berbasis IPM memiliki skor rata-rata $2,33 \quad(77,79 \%)$. Nilai ini membuktikan tingkat efektivitas yang bagus dari strategi koordinatif pengendalian antar-dokumen perencanaan khususnya dalam mengendalikan rumusan awal kebijakan RKPD. Penguatan koordinasi tersebut mencerminkan kinerja pengendalian rancangan awal RKPD sesuai arah konsistensi yang positif antara perencanaan dan penganggaran antar dokumen perencanaan yang ada.

Terkait dengan mekanisme koordinasi pelaksanaan pembangunan skor rata-rata mencapai 2,32 (77,57\%) atau masuk kedalam klasifikasi “kuat". Pengendalian pelaksanaan RKPD Pemerintah Kabupaten Sambas dinilai cukup berhasil dalam mengkoordinasikan pengendalian pelaksanaan RKPD dan menjamin bahwa prioritas pembangunan tahunan daerah dijadikan pedoman penyusunan rancangan kebijakan umum APBD (KUA), prioritas plafon anggaran sementara (PPAS) dan anggaran pendapatan dan belanja daerah (APBD). Posisi atribut nilai kuat yang bagus 
adalah mendekati angka atau poin 90\%. Oleh karena itu nilai $77,57 \%$ ini masih perlu perhatian atau penguatan yang lebih sehingga kekuatan koordinasi semakin baik. Untuk tahapan mekanisme koordinasi evaluasi hasil RKPD mempunyai skor rata-rata $2,30(76,76 \%)$ atau masuk kedalam klasifikasi "kuat", namun demikian nilai ini masih perlu penguatan karena nilai ideal adalah $90 \%$.

Penguatan Koordinasi Fungsional RKPD untuk pembangunan berbasis IPM sebagaimana yang telah diuraikan di atas, meliputi mekanisme koordinasi pengendaian rancangan awal RKPD, koordinasi pengendalian pelaksanaan, dan koordinasi evaluasi hasil RKPD. Nilai skor pada tahapan ini adalah sebesar 2,31 (76,70\%) yang masuk ke dalam klasifikasi "kuat". Kinerja Kabupaten Sambas dalam melakukan koordinasi fungsional khususnya yang dikoordinasikan oleh Badan Perencanaan Pembangunan Daerah (Bappeda) Kabupaten Sambas dinilai efektif, kuat dan konsisten. Hanya saja nilai pencapaian persentase total sebesar $76,70 \%$ masih belum optimal, karena nilai yang baik untuk kriteria "kuat" mendekati angka 90\%.

Tabel 4. Analisis Penguatan Koordinasi Fungsional Rencana Kerja Pemerintah Daerah (RKPD) di Kabupaten Sambas, 2016.

Table 4. Analysis of Functional Coordination Strengthening of Local Government Work Plan (RKPD) in Sambas Regency, 2016.

\begin{tabular}{|c|c|c|c|}
\hline No & Indikator/ Indicator & Skor/Score & $\begin{array}{l}\text { Persentase (\%)/ } \\
\text { Percentage (\%) }\end{array}$ \\
\hline 1 & \multicolumn{3}{|c|}{ Koordinasi pengendalian rancangan awal RKPD/Controling coordination early draft RKPD } \\
\hline a. & Keterlibatan dalam rapat/ Involvement in meeting & 2.63 & 87.87 \\
\hline b. & $\begin{array}{l}\text { Keaktifan dalam memberikan ide-ide/ pendapat dalam rapat / } \\
\text { Activeness in giving ideas /opinions in meetings }\end{array}$ & 2.18 & 72.72 \\
\hline c. & $\begin{array}{l}\text { Kepatuhan mentaati segala peraturan/ kesepakatan yang berlaku / } \\
\text { Compliance obey all the rules / agreements in force }\end{array}$ & 2.47 & 82.57 \\
\hline \multirow[t]{2}{*}{ d. } & $\begin{array}{l}\text { Keterlibatan dalam memberikan koreksi terhadap kesepakatan } \\
\text { yang berlaku / Involvement in providing corrections to the applicable } \\
\text { agreement }\end{array}$ & 2.04 & 68.00 \\
\hline & Rata-rata / Average & 2.33 & 77.79 \\
\hline
\end{tabular}

2 Mekanisme koordinasi pengendalian pelaksanaan RKPD/Controling coordination mechanism of RKPD implementation

a. $\quad$ Kegiatan dalam pertemuan rutin/Activities in regular meetings $\quad 2.38 \quad 79.54$

b. Kegiatan rapat konsultatif/Consultative meeting activities $\quad 2.27 \quad 75.75$

c. Kegiatan konfirmasi/Activity confirmation $\quad 2.40 \quad 80.00$

d. Kegiatan rapat teknis/Technical meeting activities $\quad 2.25 \quad 75.00$

$\begin{array}{lll}\text { Rata-rata/Average } & 2.32 & 77.57\end{array}$

3 Mekanisme koordinasi evaluasi hasil RKPD/Coordination mechanisms RKPD result

a. Kegiatan kunjungan ke lapangan/Field survey activities $\quad 2.34 \quad 78.03$

b. Kegiatan pembahasan/pemecahan masalah/Activity discussion/ $\quad 2.34 \quad 78.03$ problem solving

c. Kegiatan pelaporan/Reporting activity $\quad 2.22 \quad 74.24$

d. Rata-rata/Average $\quad 2.30 \quad 76.76$

4 Mekanisme Pelaksanaan Koordinasi Pembangunan/ Development Coordination Mechanism Implementation

a. Koordinasi pengendalian rancangan awal RKPD/ $\quad 2.33 \quad 77.79$

b. Koordinasi pengendalian pelaksanaan RKPD/Coordination of $\quad 2.32 \quad 75.57$ controlling RKPD implementation

c. Koordinasi evaluasi hasil RKPD/Coordination of controlling RKPD $\quad 2.30 \quad 76.76$ result

d. Rata-rata/Average 2.31

Total Nilai Rata-Rata/Total of Averages Value

2.32

76.70

Sumber: Data Primer diolah, 2016/Source: Primary Data Processed, 2016 
Berdasarkan hasil analisis diketahui bahwa proses koordinasi dalam penyusunan RKPD lingkup Kabupaten Sambas sudah memiliki kinerja yang baik. Kaitannya dengan potensi wilayah Kabupaten Sambas sebagai wilayah pesisir dengan potensi sumber daya ikan yang besar maka arahan penyusunan RKPD untuk mencapai IPM yang baik maka harus disesuaikan dengan potensi wilayahnya. RKPD sebagai basis penyusunan alokasi belanja daerah sangat berpengaruh terhadap pencapaian IPM. Hasil penelitian Putra dan Ulupui (2015), menunjukkan bahwa pendapatan asli daerah dan dana alokasi khusus secara konsisten mampu meningkatkan IPM. Dengan kinerja koordinasi yang baik dalam penyusunan RKPD di Kabupaten Sambas maka berdasarkan hasil penelitian tidak menutup kemungkinan pembangunan di sektor perikanan di Wilayah Kabupaten Sambas dapat dicapai sebagai salah satu motor penggerak perekonomian wilayah ini.

\section{KESIMPULAN DAN IMPLIKASI KEBIJAKAN}

\section{Kesimpulan}

Pembangunan manusia di Kabupaten Sambas mengalami fluktuatif dalam periode 2010-2015, namun secara agregat mengalami peningkatan. Penurunan nilai capaian IPM di Kabupaten Sambas menunjukkan adanya penurunan tingkat kesejahteraan masyarakat secara agregat. Penurunan tingkat kesejahteraan yang dicerminkan oleh nilai IPM berkorelasi dengan penurunan laju pertumbuhan nilai PDRB per kapita. Perekonomian Kabupaten Sambas yang tergantung pada sektor pertanian, kehutanan dan perikanan menunjukkan bahwa banyak masyarakat yang tergantung pada sektor tersebut, sehingga pertumbuhan pada sektor ini sangat berpengaruh terhadap nilai capaian IPM. Pada periode tahun 2013-2014 semua sub sektor cenderung mengalami penurunan pertumbuhan PDRB, namun untuk sub sektor perikanan tetap meningkat. Ini menunjukkan sub sektor perikanan lebih stabil dan dapat diandalkan sebagai sub sektor unggulan. Peningkatan nilai PDRB pada sub sektor perikanan telah menunjukkan bahwa Kabupaten Sambas merupakan wilayah pesisir dengan potensi sumber daya ikan yang cukup besar.

Hasil analisis penguatan koordinasi fungsional RKPD menunjukkan bahwa koordinasi lingkup SKPD di Kabupaten Sambas sudah memiliki kinerja yang baik, yaitu dengan rata-rata nilai skor secara keseluruhan sebesar 2,32 $(77,21 \%)$ dan masuk kedalam klasifikasi "kuat" dengan rincian (1) mekanisme koordinasi pengendaian rancangan awal RKPD tergolong "kuat" dengan skor rata-rata 2,33 atau $77,79 \%$; (2) mekanisme koordinasi pengendalian pelaksanaan RKPD tergolong "cukup kuat" dengan skor rata-rata 2,32 atau $75,57 \%$; (3) mekanisme koordinasi evaluasi hasil RKPD tergolong "kuat" dengan skor rata-rata 2,30 atau $76,76 \%$, dan; (4) mekanisme pelaksanaan koordinasi pembangunan memiliki nilai atribut "kuat" dengan skor rata-rata 2,31 atau $76,70 \%$. Kinerja yang baik ini dapat menjadi modal utama dalam proses perencanaan pembangunan Kabupaten Sambas sebagai wilayah pesisir dan perbatasan dengan mengalokasikan Pendapatan Asli Daerah (PAD) dan Dana Alokasi Khusus (DAK) ke dalam sektor perikanan, pariwisata, industri, transportasi yang berkaitan dengan pesisir sehingga dapat menjadikan Kabupaten Sambas menjadi salah satu wilayah perbatasan yang berkembang.

\section{Implikasi Kebijakan}

Untuk mencapai Indeks Pembangunan Manusia (IPM) yang tinggi di Kabupaten Sambas tidak semata-mata hanya pada pertumbuhan ekonomi tapi dari segala aspek. Dalam rangka mencapai nilai IPM bukan hanya menjadi program kerja Bappeda namun merupakan program kerja seluruh SKPD Pemerintah Kabupaten Sambas. Komitmen kepala daerah dalam mendorong SKPD mengawal capaian nilai IPM dilaksanakan melalui strategi penguatan koordinasi perencanaan. Namun keberhasilan ini perlu diperkuat dengan cara meningkatkan partisipasi masyarakat dan swasta. Kabupaten Sambas telah ditetapkan sebagai kawasan minapolitan beserta kabupaten lain yang berada di kawasan pesisir. Mewujudkan kawasan minapolitan diperlukan upaya maksimal dan kerjasama antar para pihak kebijakan, program dan kegiatan pembangunan sektor kelautan dan perikanan memerlukan penyesuaian agar dapat memenuhi kebutuhan ekonomi dan terfokus pada peningkatan kesejahteraan rakyat melalui peningkatan nilai capaian IPM.

\section{UCAPAN TERIMAKASIH}

Penulis mengucapkan terima kasih dan penghargaan yang setinggi-tingginya kepada Pemerintah Kabupaten Sambas khususnya kepada yang terhormat bapak Sudaryanto Kepala Bappeda 
Kabupaten Sambas atas dukungannya dalam mensupport data dan membantu mendiskusikan penelitian ini dengan tim TAPD dan para pejabat struktural SKPD lainnya yang di ikutsertakan dalam diskusi sesuai instrumen penelitian. Ucapan terima kasih pun kami sampaikan kepada dewan redaksi jurnal sosial ekonomi kelautan dan perikanan atas masukan dan perbaikannya terhadap karya tulis ini.

\section{DAFTAR PUSTAKA}

Badan Pusat Statistik Kabupaten Sambas. 2015. Produk Domestik Regional Bruto Kabupaten Sambas Menurut Lapangan Usaha 2011 - 2015. BPS Kab. Sambas. Sambas.

Badan Pusat Statistik Provinsi Kalimantan Barat. 2015. Indeks Pembangunan Manusia Provinsi Kalimantan Barat. BPS Provinsi Kalbar. Pontianak.

Badan Perencanaan Pembangunan Daerah (Bappeda) Kabupaten Sambas. 2015. Laporan Tahunan Bappeda Kabupaten Sambas 2015. Bappeda Kab. Sambas. Sambas.

Brata, A.G. 2005. Investasi Sektor Publik Lokal, Pembangunan Manusia dan Kemiskinan. Lembaga Penelitian Universitas Atma Jaya. Yogyakarta.

Denzin, N. K. dan Y.S. Lincoln. 1994. Introduction: Entering The Field of Qualitative Research in Denzin, N.K and Lincoln, Y.S [Eds]. 1994. Handbook of Qualitative Research. Sage Publications, Inc. United States of America. 1-18p.

Emzir. 2008. Metodologi Penelitian Pendidikan Kuantitatif\&Kualitatif. Jakarta: Raja Grafindo Persada. Jakarta.

Lembaga IImu Pengetahuan Indonesia (LIPI). 2003. Workshop Pembangunan Daerah Perbatasan Indonesia. http://lipi.go.id/ berita/workshop-pembangunan-daerah-perbatasan-indonesia/186 diakses pada 22 desember 2016).

Putra, P.G.M. dan I.G.K.A Ulupui. 2015. Pendapatan Asli Daerah, Dana Alokasi Umum dan Dana Alokasi Khusus Untuk Meningkatkan Indeks Pembangunan Manusia. E-Jurnal Akuntansi Universitas Udayana 11.3 (2015). Universitas Udayana. Denpasar.

Sitepu, R. K. dan B. M. Sinaga. 2012. Dampak Investasi Sumber daya Manusia Terhadap Pertumbuhan Ekonomi Dan Kemiskinan Di Indonesia: Pendekatan Model Computable General Equilibrium. Jurnal Soca (Socio-Economic Of Agriculturre And Agribusiness). https://ojs.unud. ac.id/index.php/soca/article/view/4203>. Date accessed: 25 November 2016.
Sjafii, A. 2009. Pengaruh Investasi Fisik dan Investasi Pembangunan Manusia Terhadap Pertumbuhan Ekonomi Jawa Timur 1990 - 2004. Journal of Indonesia Applied Economics. Vol. 3 No. 1 Mei 2009, 59 -76. Fakultas Ekonomi dan Bisnis Universitas Brawijaya. Malang.

Stake, R. E. 2005. Case Study Methods in Educational Research: Seeking Sweet Water. In R. M. Jaeger (Ed.) Complementary methods for research in education 2nd Edition (pp, 401414). American Educational Research Association: Washington, DC.

Suliswanto, M.S.W. 2010. Pengaruh Produk Domestik Bruto (PDB) dan Indeks Pembangunan Manusia (IPM) Terhadap Angka Kemiskinan di Indonesia. Jurnal Ekonomi Pembangunan. Vol 8 No 2 Desember 2010. UMM. Malang.

Wiranto, T. 2004. Pembangunan Wilayah Pesisir dan Laut Dalam Rangka Pembangunan Perekonomian Daerah. Makalah. Disampaikan pada Sosialisasi Nasional Program MFCDP, 22 September 2004. Bappenas. Jakarta.

Yacoub, Y. 2012. Pengaruh Tingkat Pengangguran Terhadap Tingkat Kemiskinan Kabupaten/Kota di Provinsi Kalimantan Barat. Jurnal Eksos Vol8, Nomor 3, Oktober 2012. Hal 176 - 185. Politeknik Negeri Pontianak. Pontianak. 